\title{
INVENTARISASI JAMUR MAKROSKOPIS DI HUTAN BUKIT DANAU DESA PENIRAMAN KECAMATAN SUNGAI PINYUH KABUPATEN MEMPAWAH
}

\author{
Salmiah $^{1}$, Masnur Turnip ${ }^{1}$, Siti Ifadatin $^{1}$ \\ ${ }^{1}$ Program Studi Biologi, Fakultas MIPA, Universitas Tanjungpura, Pontianak \\ Email korespondensi: salmiahmia556@gmail.com
}

\begin{abstract}
Macroscopic mushrooms are one of the important biodiversity in the ecosystem of forests and human life. Research related to macroscopic mushrooms in West Kalimantan has already been done, but have never done in some areas, which is in the forest of Bukit Danau Peniraman Village of Mempawah regency. This research aims to determine the types of macroscopic mushrooms that exist in the forest of Bukit Danau Peniraman Village of Sungai Pinyuh district, Mempawah regency. Sampling of fungi using exploration methods by exploring the forest according to the transect pathway. The results showed that there were 20 types of macroscopic mushrooms consisting of 5 orders, 13 families, and 17 generas. Fungi that most commonly found came from an order of Polyporales and the fewest orders are the order of Dacrymycetales, the order of Hymenochaetales, and the order of Xylariales. Macroscopic mushrooms found in the forest of Bukit Danau Peniraman Village of Sungai Pinyuh district, Mempawah regency, fungi most commonly grew at substrate of dead tree.
\end{abstract}

Keywords: Macroscopic mushrooms, Polyporales, The Forest of Bukit Danau Peniraman Village.

\section{PENDAHULUAN}

Kalimantan Barat mempunyai hutan yang tersebar luas di berbagai daerah salah satunya hutan yang terdapat di Bukit Danau Desa Peniraman. Kawasan hutan Bukit Danau masih menyimpan berbagai jenis flora dan fauna serta kaya akan sumber daya hayati, salah satunya keanekaragaman jenis jamur makroskopis.

Jamur adalah salah satu keanekaragaman yang memperkaya jenis mahkluk hidup. Jamur makroskopis memiliki ciri khas yaitu basidium. Jamur makroskopis hidup sebagai saprofit pada sisa-sisa makhluk hidup, seperti merang padi, serasah daun, dan pohon mati (Subowo, 1992). Menurut Suharna (1993) jamur makroskopis memiliki peran sebagai dekomposer yang membantu dekomposisi bahan organik dalam ekosistem hutan. Oleh sebab itu, jamur ikut serta dalam menyuburkan tanah dengan menyediakan nutrisi bagi tumbuhan sehingga tumbuhan dapat tumbuh dengan subur.

Hutan Bukit Danau merupakan hutan sekunder yang terletak di Bukit Danau Desa Peniraman Kecamatan Sungai Pinyuh Kabupaten Mempawah. Di hutan Bukit Danau terdapat kegiatan masyarakat seperti penebangan pohon, penggerusan tanah, serta pembukaan lahan. Pembukaan lahan dengan cara berpindah-pindah menyebabkan perubahan vegetasi sehingga mengakibatkan banyaknya cahaya yang masuk ke lantai hutan. Menurut Tarsia (2010) banyaknya cahaya yang masuk ke lantai hutan dapat menyebabkan pertumbuhan jamur pada spesies tertentu menjadi terhambat. Kegiatan manusia yang dilakukan di hutan tersebut dikhawatirkan dapat mengancam keberadaan jamur makroskopis sehingga perlu dilakukan penelitian di hutan Bukit Danau. Penelitian tentang inventarisasi jenis jamur makroskopis perlu dilakukan untuk mengetahui jenis dan menghindari ancaman kepunahan terhadap keberadaan jamur di Hutan Bukit Danau.

Tujuan penelitian ini untuk mengetahui jenis-jenis jamur makroskopis dan ciri-ciri jamur makroskopis yang ditemukan di Hutan Bukit Danau Desa Peniraman, Kecamatan Sungai Pinyuh, Kabupaten Mempawah. Penelitian ini diharapkan dapat memberikan informasi mengenai jenis-jenis jamur makroskopis sehingga dapat membantu dalam upaya pengembangan, pembudidayaan, serta pelestarian jenis jamur makroskopis yang ada di kawasan Hutan Bukit Danau Desa Peniraman, Kecamatan Sungai Pinyuh, Kabupaten Mempawah.

\section{BAHAN DAN METODE}

\section{Waktu dan Tempat Penelitian}

Penelitian dilakukan selama 3 bulan yaitu pada bulan Mei sampai Juli 2019 di Kawasan Hutan Bukit Danau Desa Peniraman, Kecamatan Sungai 
Pinyuh, Kabupaten Mempawah. Identifikasi jamur makroskopis dilakukan di Laboratorium Biologi Fakultas Matematika dan Ilmu Pengetahuan Alam Universitas Tanjungpura Pontianak.

\section{Deskripsi Umum Lokasi Penelitian}

Desa Peniraman terletak dikecamatan Sungai Pinyuh, Kabupaten Mempawah yang memiliki luas 17,78 ha, memiliki jarak $\pm 7 \mathrm{~km}$ dari ibu kota Kecamatan Sungai Pinyuh dan berjarak $\pm 27 \mathrm{~km}$ dari ibu kota Kabupaten Mempawah (Gambar 1). Desa Peniraman terletak pada $0^{\circ} 11^{\prime} \mathrm{LU}-0^{\circ} 25^{\prime} \mathrm{LU}$ dan $108^{\circ} 58^{\prime}$ BT $-109^{\circ} 21,5^{\prime}$ BT, mempunyai suhu udara berkisar $25-32{ }^{\circ} \mathrm{C}$ dengan curah hujan rata - rata pertahunnya $322,4 \mathrm{~mm}$ pertahun. Hutan Bukit Danau terletak di Desa Peniraman, memiliki luas wilayah 2.300 ha.

\begin{abstract}
Alat dan Bahan
Alat-alat yang digunakan dalam penelitian ini adalah alat tulis, GPS (Global Positioning System), higrometer, kamera, kantong plastik, kertas label, kertas HVS, luxmeter, masker, $\mathrm{pH}$ tester, selotip, sprayer, sarung tangan,toples atau botol. Bahan yang digunakan dalam penelitian ini yaitu Alkohol $70 \%$.
\end{abstract}

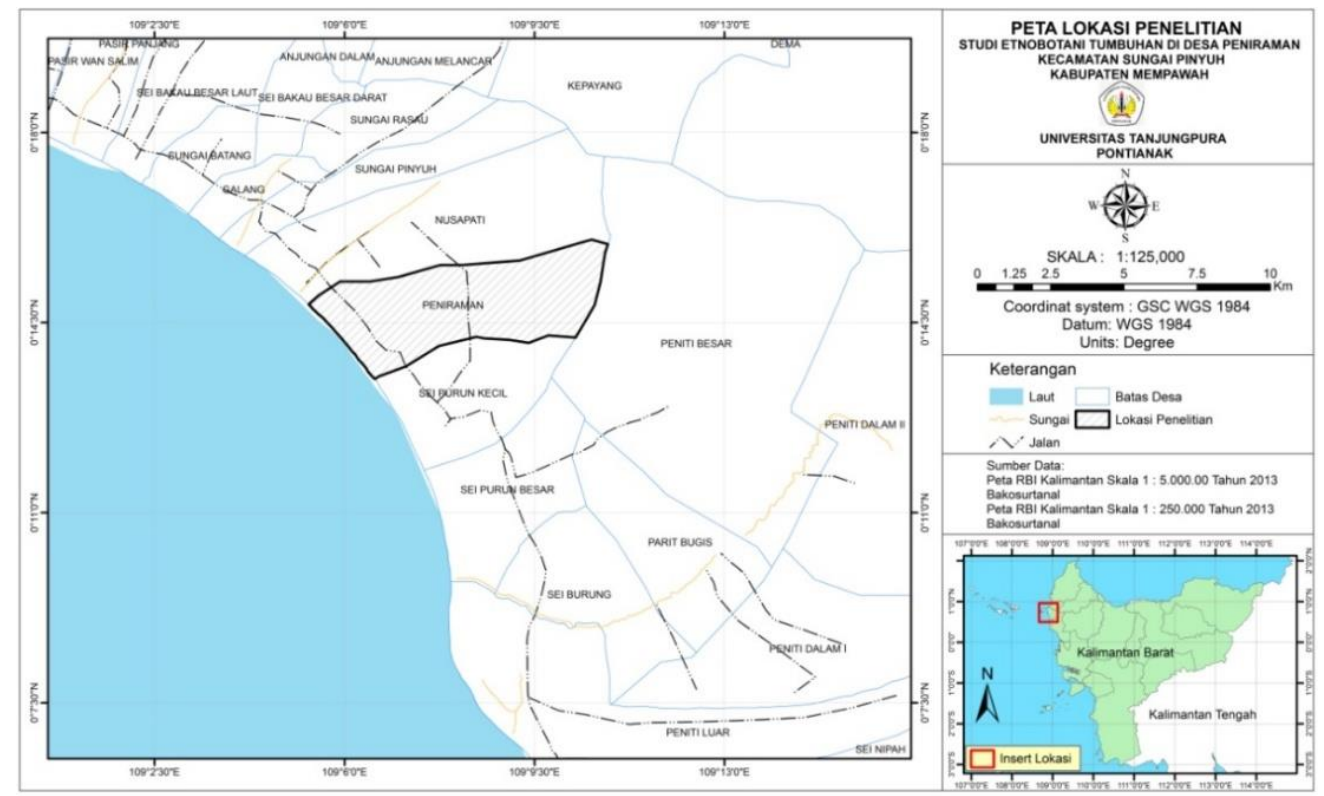

Gambar 1 Letak Lokasi Bukit Danau Desa Peniraman

\section{Cara Kerja}

Pengambilan Sampel Jamur Makroskopis

Pengambilan sampel dilakukan dengan metode jelajah (Cruise Method) (Rugayah dan Pratiwi, 2004) yaitu dengan cara menjelajahi hutan Bukit Danau sesuai dengan jalur transek. Pengambilan sampel jamur dengan melihat ciri-ciri seperti, warna tubuh jamur, tekstur, bentuk cup, tepian cup, permukaan cup, lebar cup, bentuk bilah, dan ada tidaknya tangkai. Setiap jamur makroskopis yang didapat di lapangan baik yang terdapat pada substrat kayu, tanah, dan serasah diambil kemudian dimasukkan ke dalam kantong plastik dan diberi label untuk diidentifikasi di laboratorium. pengukuran faktor lingkungan yang meliputi jenis substrat, suhu, kelembaban, intensitas cahaya, dan tingkat keasaman substrat $(\mathrm{pH})$.

\section{Identifikasi Jenis Jamur Makroskopis}

Sampel diidentifikasi menggunakan buku Introductory Mycology oleh Alexopoulus et al. (1996), Mushroom and Other Fungi of the Midcontinental United States oleh Huffman et al. (2008), dan A Guide to Common Fungi of The Hunter - Central Rivers Region oleh moore et al. (2014), Polypores of British Columbia oleh Ginn's (2017) serta skripsi maupun jurnal mengenai jamur makroskopis.

\section{Pembuatan Herbarium dan Kunci Deteminasi}

Pembuatan herbarium ada dua yaitu herbarium basah dan herbarium kering. Kunci determinasi yang dipakai adalah kunci determinasi dikotom (bercabang dua).

\section{Penyajian data}

Hasil yang diperoleh disajikan dalam bentuk dokumentasi (foto) (Gambar 2), tabel, dan deskripsi.

\section{HASIL DAN PEMBAHASAN}




\section{Hasil}

Berdasarkan penelitian yang telah dilakukan di Hutan Bukit Danau Desa Peniraman Kecamatan Sungai Pinyuh Kabupaten Mempawah, ditemukan 5 ordo, 13 famili, dan 17 genus. Jenis jamur yang paling banyak ditemukan terdapat pada pohon mati sedangkan yang paling sedikit terdapat pada substrat pohon hidup (Tabel 1).

Tabel 1 Jenis Jenis Jamur Makroskopis di Hutan Bukit Danau Desa Peniraman Kecamatan Sungai Pinyuh Kabupaten Mempawah.

\begin{tabular}{|c|c|c|c|c|}
\hline No. & Ordo & Famili & Genus & Substrat \\
\hline \multirow[t]{7}{*}{1.} & Agaricales & Bolbitaceae & Conocybe sp. & Tanah \\
\hline & & Coprinaceae & Coprinus sp. & Tanah \\
\hline & & Mycenaceae & Mycena sp. & Pohon mati \\
\hline & & Pluteaceae & Volvariella sp. & Tanah \\
\hline & & Polyporaceae & Panus sp. & Pohon mati \\
\hline & & Scizhophyllaceae & Scizhophyllum sp. & Pohon mati \\
\hline & & Tricholomataceae & Delicatula sp. & Tanah \\
\hline \multirow[t]{10}{*}{2.} & Polyporales & Ganodermataceae & Ganoderma sp. 1 & Pohon mati \\
\hline & & & Ganoderma sp. 2 & Pohon hidup \\
\hline & & Lentinaceae & Lentinus sp. & Pohon mati \\
\hline & & Polyporaceae & Earliella sp. & Pohon mati \\
\hline & & & Hexagonia sp. & Pohon mati \\
\hline & & & Polyporus sp. 1 & Pohon mati \\
\hline & & & Pycnoporus sp. & Pohon mati \\
\hline & & & Polyporus sp. 2 & Tanah \\
\hline & & & Trametes sp. 1 & Pohon mati \\
\hline & & & Trametes sp. 2 & Pohon mati \\
\hline 3. & Dacrymycetales & Dacrymycetaceae & Dacryopinax sp. & Pohon mati \\
\hline 4. & Hymenochaetales & Hymenochaetaceae & Mensularia sp. & Pohon mati \\
\hline 5. & Xylariales & Xylariaceae & Daldania sp. & Pohon mati \\
\hline
\end{tabular}

Tabel 2 Faktor Lingkungan di Kawasan Hutan Bukit Danau Desa Peniraman Kecamatan Sungai Pinyuh Kabupaten Mempawah.

\begin{tabular}{|c|c|c|c|c|c|}
\hline No. & Genus & Suhu & Kelembapan & Cahaya & pH \\
\hline 1. & Conocybe sp. & $28^{\circ} \mathrm{C}$ & $75 \%$ & $325 \operatorname{lux}$ & 6,6 \\
\hline 2. & Coprinus sp. & $28^{\circ} \mathrm{C}$ & $78 \%$ & $421 \operatorname{lux}$ & 6,5 \\
\hline 3. & Daldinia sp. & $29^{\circ} \mathrm{C}$ & $70 \%$ & 769 lux & 6,5 \\
\hline 4. & Dacryopinax sp. & $28^{\circ} \mathrm{C}$ & $70 \%$ & 322 lux & 6,5 \\
\hline 5. & Earliella sp. & $30^{\circ} \mathrm{C}$ & $78 \%$ & 987 lux & 6,8 \\
\hline 6. & Ganoderma sp. 1 & $31^{\circ} \mathrm{C}$ & $68 \%$ & 1148 lux & 6,8 \\
\hline 7. & Ganoderma sp. 2 & $32^{\circ} \mathrm{C}$ & $68 \%$ & $987 \operatorname{lux}$ & 6,8 \\
\hline 8. & Hexagonia sp. & $30^{\circ} \mathrm{C}$ & $69 \%$ & 831 lux & 6,7 \\
\hline 9. & Lentinus sp. & $28^{\circ} \mathrm{C}$ & $79 \%$ & 278 lux & 6,5 \\
\hline 10. & Panus sp. & $29^{\circ} \mathrm{C}$ & $72 \%$ & 531 lux & 6,7 \\
\hline 11. & Delicatula sp. & $28^{\circ} \mathrm{C}$ & $79 \%$ & 293 lux & 6,5 \\
\hline 12. & Mensularia sp. & $30^{\circ} \mathrm{C}$ & $72 \%$ & $986 \operatorname{lux}$ & 6,7 \\
\hline 13. & Mycena sp. & $28^{\circ} \mathrm{C}$ & $76 \%$ & 438 lux & 6,5 \\
\hline 14. & Polyporus sp. & $29^{\circ} \mathrm{C}$ & $71 \%$ & $678 \operatorname{lux}$ & 6,7 \\
\hline 15. & Pycnoporus sp. & $29^{\circ} \mathrm{C}$ & $75 \%$ & 654 lux & 6,7 \\
\hline 16. & Polyporus sp. & $29^{\circ} \mathrm{C}$ & $75 \%$ & 832 lux & 6,8 \\
\hline 17. & Scizhophyllum sp. & $29^{\circ} \mathrm{C}$ & $72 \%$ & 752 lux & 6,8 \\
\hline 18. & Trametes sp. 1 & $30^{\circ} \mathrm{C}$ & $76 \%$ & 967 lux & 6,8 \\
\hline 19. & Trametes sp. 2 & $32^{\circ} \mathrm{C}$ & $72 \%$ & 1032 lux & 6,8 \\
\hline 20. & Volvariella $\mathrm{sp}$. & $28^{\circ} \mathrm{C}$ & $79 \%$ & $342 \operatorname{lux}$ & 6,7 \\
\hline
\end{tabular}




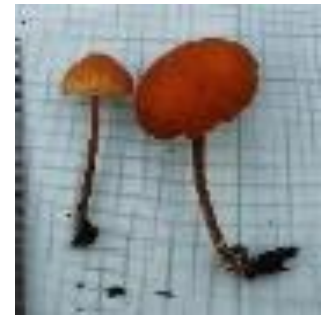

a.

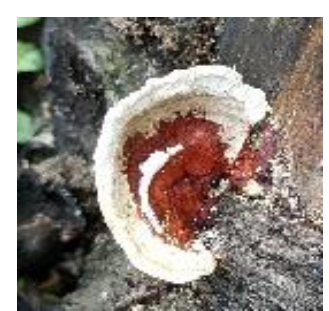

e.

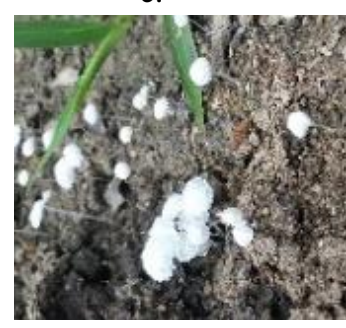

i.

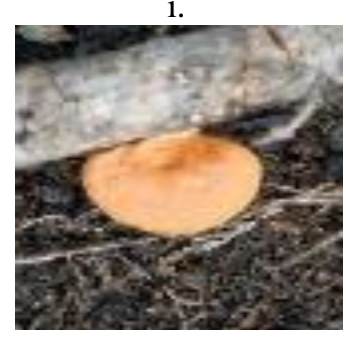

$\mathrm{m}$.

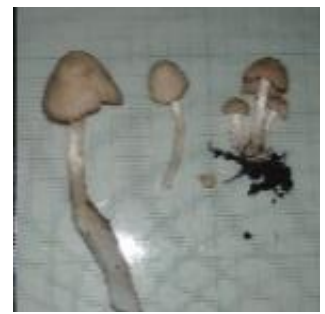

q.

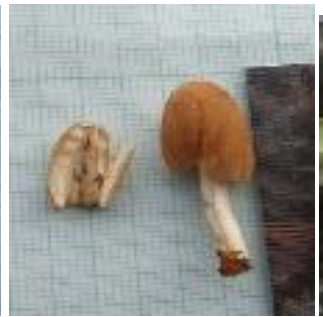

b.

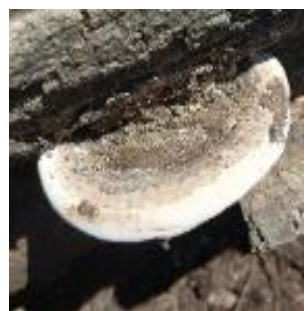

f.

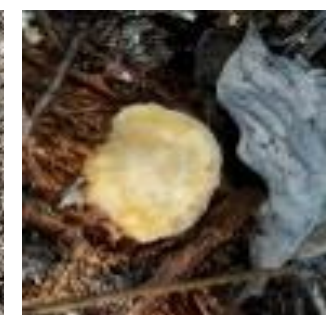

j.

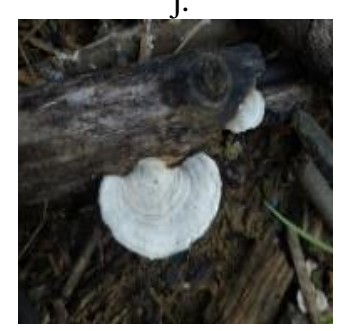

n.

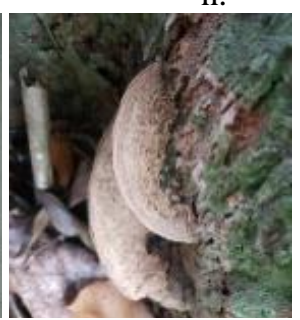

r.

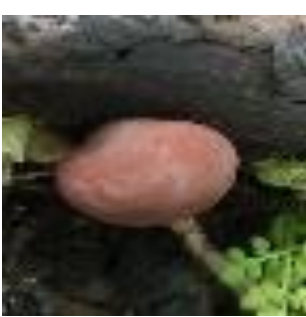

c.

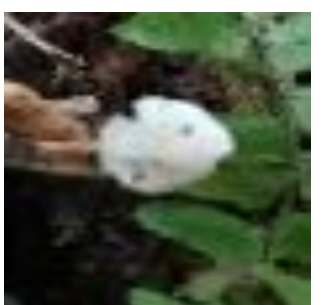

g.

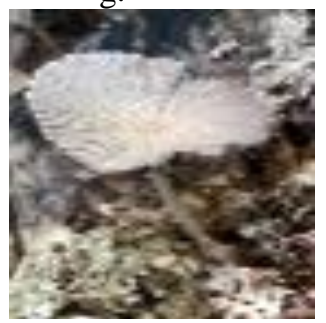

$\mathrm{k}$.

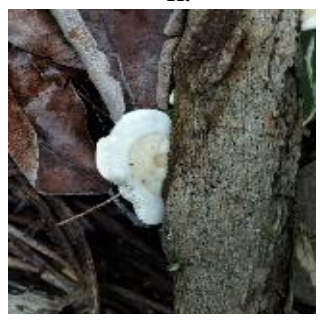

o.

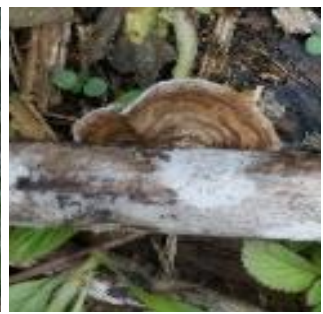

S.

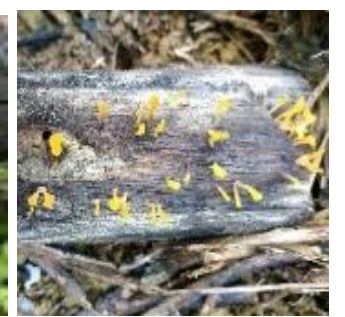

d.

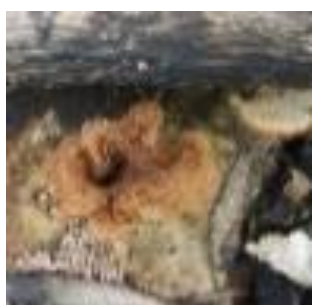

h.

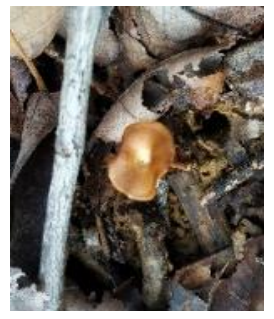

1.

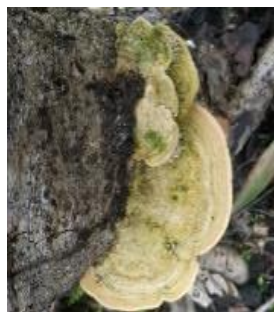

p.

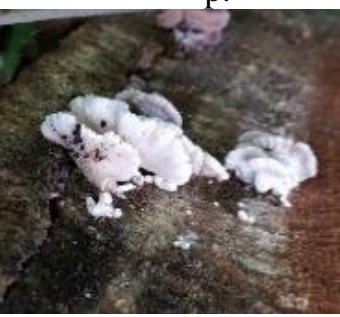

t.

Gambar 2. a. Conocybe sp., b. Coprinus sp., c. Daldinia sp., d. Dacryopinax sp., e. Earliella sp., f. Ganoderma sp. 1, g. Lentinus sp., h. Panus sp., i. Delicatula sp., j. Mensularia sp., k. Mycena sp., 1. Polyporus sp. 1, m. Pycnoporus sp., n. Polyporus sp. 2, o. Trametes sp. 1, p.Trametes sp. 1, q. Volvariella sp., r. Ganoderma sp. 2, s. Hexagonia sp., t.Scizhophyllum sp.

\section{Pembahasan}

Penelitian yang dilakukan di Hutan Bukit Danau Desa Peniraman menemukan 4 ordo dan 11 famili dari kelas Basidiomycetes. Jamur makroskopis yang ditemukan di Hutan Bukit Danau terdiri atas anggota ordo Agaricales, Polyporales, Dacrymycetales, dan Hymenochaetales. Jenis jamur makroskopis ditemukan pada substrat pohon hidup, pohon mati, dan tanah. Suhardiman (1995) menyatakan, jamur makroskopis anggota Basidiomycetes tumbuh pada lingkungan yang mempunyai kandungan karbohidrat, lignin, dan selulosa. Kandungan tersebut terdapat pada substrat yang digunakan sebagai sumber nutrisi bagi jamur. Menurut Noverita et al. (2017) jamur makroskopis umumnya hidup saprofit dihabitat asal dengan peran sebagai pengurai bahan organik, seperti kayu lapuk, pohon mati, dan serasah. 
Penelitian yang dilakukan di Hutan Bukit Danau Desa Peniraman menemukan 4 ordo dan 11 famili dari kelas Basidiomycetes. Jamur makroskopis yang ditemukan di Hutan Bukit Danau terdiri atas anggota ordo Agaricales, Polyporales, Dacrymycetales, dan Hymenochaetales. Jenis jamur makroskopis ditemukan pada substrat pohon hidup, pohon mati, dan tanah. Suhardiman (1995) menyatakan, jamur makroskopis anggota Basidiomycetes tumbuh pada lingkungan yang mempunyai kandungan karbohidrat, lignin, dan selulosa. Kandungan tersebut terdapat pada substrat yang digunakan sebagai sumber nutrisi bagi jamur. Menurut Noverita et al. (2017) jamur makroskopis umumnya hidup saprofit dihabitat asal dengan peran sebagai pengurai bahan organik, seperti kayu lapuk, pohon mati, dan serasah.

Berdasarkan penelitian yang telah dilakukan, jamur makroskopis yang paling banyak ditemukan berasal dari ordo Polyporales.Banyaknya Ordo Polyporales yang ditemukan karena ordo Polyporales mampu beradaptasi dengan lingkungan dibandingkan ordo lainnya. Jamur ordo Polyporales ditemukan tumbuh pada substrat pohon mati, kayu lapuk, dan tanah karena substrat tersebut mengandung nutrisi untuk pertumbuhan jamur tersebut. Hal ini sesuai dengan pernyataan Suhardiman (1995) bahwa ordo Polyporales termasuk kelompok jamur yang mempunyai banyak spesies sehingga sering ditemukan pada substrat kayu maupun serasah. Ordo ini juga mampu beradaptasi dengan lingkungan yang kurang mendukung untuk pertumbuhannya. Saputra (2015) menyatakan bahwa Polyporales biasa disebut juga polypores. Hal ini dikarenakan adanya pori-pori pada bilah. Tubuh buah ada yang mirip kerak, papan dan payung. Apabila sudah tua pada umumnya bertekstur kuat, keras, bergabus dan berkayu. Sebagian besar spesies dari ordo Polyporales dapat mengakibatkan penyakit pada kayu dan pohon. Ordo Polyporales mempunyai spesies cukup banyak dari Famili Polyporaceae.

Ordo yang paling sedikit ditemukan yaitu ordo Hymenochaetales, ordoDacrymycetales, dan ordo Xylariales yang masing-masing terdiri dari 1 jenis.Sastrahidayat (2011) menyatakan bahwa ordo Hymenochaetales kebanyakan saprofit pada kayu busuk, basidiocarp berwarna coklat emas sampai coklat kemerahan. Kemudian, ordo Xylariales. Jamur ini ditemukan tumbuh pada pohon yang sudah mati. Jamur ini ditemukan pada area yang tidak ternaungi dengan suhu $29^{\circ} \mathrm{C}$ dengan kelembaban $73 \%$ dan intensitas cahaya 816 lux. Jamur
dariDacrymycetales memiliki warna coklat, jingga, kuning, dengan bentuk badan buah seperti garpu, spatula, tektur lunak, berdaging (Asnah, 2010). Jamur ini ditemukan pada pohon yang sudah mati.

Berdasarkan hasil pengukuran faktor lingkungan pada tiap genus jamur makroskopis berbeda-beda. Pengamatan suhu berkisaran $28-32^{\circ} \mathrm{C}$, sesuai dengan pernyataan Arif et al. (2007), bahwa suhu optimum untuk pertumbuhan jamur berkisar $22-35{ }^{\circ} \mathrm{C}$. Jamur yang ditemukan pada penelitian ini termasuk ke dalam jamur mesofilik. Jamur mesofilik tumbuh pada kisaran suhu $25-37^{\circ} \mathrm{C}$ (Suriawiria, 1986).

Hasil pengukuran kelembapan berkisar antara 6879\% (Tabel 2). Gandjar et al., (2006) menyatakan bahwa kelembapan jamur berkisar antara $70-81 \%$. Hasil pengukuran intensitas cahaya pada penelitian ini berkisar antara 378-1253 lux (Tabel 2). Perbedaan intensitas cahaya pada masing-masing spesies disebabkan oleh penutupan dari pohon yang tidak merata, tidak meratanya cahaya masuk dikarenakan adanya penebangan pohon. Banyaknya penebangan pohon menyebabkan berkurangnya pohon yang menaungi lantai hutan sehingga cahaya yang masuk lebih banyak. Hal ini yang membuat serasah dan tanah menjadi kering dan tidak lembab sehingga jamur tidak mampu tumbuh.

Selain suhu, kelembapan, dan intensitas cahaya, $\mathrm{pH}$ tanah juga mempengaruhi dalam ketersediaan nutrien untuk memenuhi kebutuhan hidup jamur. Hasil pengukuran $\mathrm{pH}$ tanah di Hutan Bukit Danau Desa Peniraman berkisar antara 6,5-6,8 (Tabel 2). Gunawan (2008) menyatakan bahwa makrofungi dapat tumbuh pada kisaran $\mathrm{pH}$ yang cukup luas yaitu antara 4,5-8 tergantung jenis makrofunginya. Menurut Suin (2002) faktor lingkungan sangat menentukan penyebaran dan pertumbuhan organisme. Lokasi yang didominasi oleh pohonpohon dapat menimbulkan banyaknya serasah daun maupun ranting-ranting yang berjatuhan dapat menjadi substrat bagi jamur. Ulya et al. (2017) menyatakan bahwa faktor cahaya sangat menentukan penyebaran dan pertumbuhan suatu organisme yaitu setiap spesies hanya dapat hidup pada kondisi abiotik tertentu yang berada dalam kisaran toleransi yang cocok bagi organisme tersebut.

\section{DAFTAR PUSTAKA}

Alexopoulus \& C.J. Mims CW., 1996, Introductory Mycology, John Wiley and Sons., New York. 
Protobiont (2020) Vol. 9 (1) : 1-6

Arif A, Musrizal M, Tutik K, \& Vitri H, 2007, Isolasi dan Identifikasi Jamur Kayu dari Hutan Pendidikan dan Latihan Tabo - Tabo Kecamatan Bungoro Kabupaten Pangkep, Jurnal Perennial, vol. 3, no. 2, hal. 49-54.

Asnah, 2010, Inventarisasi jamur Makroskopis di Ekowisata Tangkahan Taman Nasional Gunung Leuser Kabupaten langkat Sumatera Utara, Tesis, Universitas Sumatera Utara, Medan.

Badan Pusat Statistik Kabupaten Mempawah, 2017, Kecamatan Sungai Pinyuh Dalam Angka, Kabupaten Mempawah.

Gandjar, IW, Sjamsuridzal, \& Oetary, A, 2006, Mikologi Dasar dan Terapan, Yayasan Obor Indonesia, Jakarta.

Ginn's J, 2017, Polypores of British Columbia, Queen's Printer, Columbia.

Gunawan, A,W, 2008, Usaha Pembibitan Jamur, Penebar Swadaya, Depok.

Huffman DM, Tiffany LH, Knaphus G, \&Healy RA, 2008, Mushroom and Other Fungi of the Midcontinental United States, Second Edition, The University of Lowa Press.

Moore S \& O'Sullivan PA, 2014, A Guide to Common Fungi of The Hunter - Central Rivers Region, Hunter Local Land Services.

Noverita, Sinaga E, \&Setia TM, 2017, Jamur Makro Berpotensi Pangan dan Obat di Kawasan Cagar Alam Lembah Anai dan Cagar Alam Batang Palupuh Sumatera, Jurnal Mikologi Indonesia vol.1, no.1, hal. 15-27.
Rugayah W, \& Pratiwi, 2004, Pedoman Pengumpulan Data Keanekaragaman Flora, Pusat Penelitian Biologi-LIPI, Bogor.

Saputra A, 2015, Inventarisasi Jamur Makroskopis di Hutan Cagar Alam Durian Luncuk II Batang Hari Kecamatan Batin XXIV Kabupaten Batang Hari, Skripsi, Universitas Jambi, Jambi.

Sastrahidayat IK, 2011, Mikologi Ilmu Jamur, Universitas Brawijaya Press, Malang.

Subowo YB, 1992, Inventarisasi Jamur Kayu di Habema, Jurnal Penelitian, vol. 9, hal.6, no. 793-799.

Suharna N, 1993, Keberadaan Basidiomycetes di Cagar Alam Bantimurung, Karaenta dan Sekitarnya, Maros, Sulawesi Selatan, Puslitbang BiologiLIPI, Bogor.

Suhardiman P, 1995, Jamur Kayu, Penebar Swadaya, Jakarta.

Suin NM, 2002, Metoda Ekologi, Universitas Andalas, Padang.

Suriawiria HU., 1986, Pengantar Untuk Mengenal dan Menanam Jamur, Angkasa, Bandung.

Tarsia D, 2010, Inventarisasi Jenis Jamur Kayu di Hutan Gunung Semahung Dusun Petai Kecamatan Sengah Temila Kabupaten Landak, Skripsi, Fakultas Matematika dan Ilmu Pengetahuan Alam Universitas Tanjungpura, Pontianak.

Ulya ANA, Leksono SM, \& Khastini RO, 2017, Biodiversitas dan Potensi Jamur Basidiomycota di Kawasan Kesepuhan Cisungsang Kabupaten Lebak Banten, Jurnal Pendidikan Biologi, Vol. 10, p-ISSN 1978-3736, e-ISSN:2502-6720. 